This document is confidential and is proprietary to the American Chemical Society and its authors. Do not copy or disclose without written permission. If you have received this item in error, notify the sender and delete all copies.

\title{
Could fecal phenylacetic and phenylpropionic acids be used as indicators of health status?
}

\begin{tabular}{|c|c|}
\hline Journal: & Journal of Agricultural and Food Chemistry \\
\hline Manuscript ID & jf-2018-04102f.R1 \\
\hline Manuscript Type: & Article \\
\hline Date Submitted by the Author: & $\mathrm{n} / \mathrm{a}$ \\
\hline Complete List of Authors: & $\begin{array}{l}\text { Gutiérrez-Díaz, Isabel; Universidad de Oviedo Facultad de Medicina, } \\
\text { Department of Functional Biology; Instituto de Investigación Sanitaria del } \\
\text { Principado de Asturias (ISPA) } \\
\text { Fernández-Navarro, Tania; Universidad de Oviedo Facultad de Medicina, } \\
\text { Department of Functional Biology; Instituto de Investigación Sanitaria del } \\
\text { Principado de Asturias (ISPA), } \\
\text { Salazar, Nuria; Instituto de Productos Lacteos de Asturias, Consejo } \\
\text { Superior de Investigaciones Científicas, Microbiology and Biochemistry of } \\
\text { Dairy Products; Instituto de Investigación Sanitaria del Principado de } \\
\text { Asturias (ISPA) } \\
\text { Bartolome, Begoña; Institute of Food Science Research (CIAL), CSIC-UAM, } \\
\text { CEI UAM-CSIC, } \\
\text { Moreno-Arribas, M. Victoria; Institute of Food Science Research (CIAL), } \\
\text { CSIC-UAM, CEI UAM-CSIC } \\
\text { López, Patricia; Universidad de Oviedo Facultad de Medicina, Department } \\
\text { of Functional Biology; Instituto de Investigación Sanitaria del Principado } \\
\text { de Asturias (ISPA) } \\
\text { Suarez, Ana; Universidad de Oviedo Facultad de Medicina, Department of } \\
\text { Functional Biology; Instituto de Investigación Sanitaria del Principado de } \\
\text { Asturias (ISPA) } \\
\text { de los Reyes-Gavilan, Clara; Instituto de Productos Lacteos de Asturias, } \\
\text { Consejo Superior de Investigaciones Científicas, Microbiology and } \\
\text { Biochemistry of Dairy Products; Instituto de Investigación Sanitaria del } \\
\text { Principado de Asturias (ISPA) } \\
\text { Gueimonde, Miguel; Instituto de Productos Lácteos de Asturias - Consejo } \\
\text { Superior de Investigaciones Científicas (IPLA-CSIC), Department of } \\
\text { Microbiology and Biochemistry of Dairy Products; Instituto de Investigación } \\
\text { Sanitaria del Principado de Asturias (ISPA) } \\
\text { Gonzalez, Sonia; University of Oviedo, Functional Biology; Instituto de } \\
\text { Investigación Sanitaria del Principado de Asturias (ISPA) }\end{array}$ \\
\hline
\end{tabular}

\section{SCHOLARONE \\ Manuscripts}




\section{Could fecal phenylacetic and phenylpropionic acids be used as indicators of health} status?

Isabel Gutiérrez-Díaz ${ }^{1,2}$, Tania Fernández-Navarro ${ }^{1,2}$, Nuria Salazar ${ }^{2,3}$, Begoña Bartolomé $^{4}$, M. Victoria Moreno-Arribas ${ }^{4}$, Patricia López ${ }^{1,5}$, Ana Suárez ${ }^{1,5}$, Clara G. de los Reyes-Gavilán ${ }^{2,3}$, Miguel Gueimonde ${ }^{2,3}$ and Sonia González ${ }^{1,2^{*}}$.

${ }^{1}$ Department of Functional Biology, University of Oviedo, C/Julián Clavería s/n Oviedo, 33006 Asturias, Spain.

${ }^{2}$ Group Diet, Microbiota and Health, Instituto de Investigación Sanitaria del Principado de Asturias (ISPA), Avda. Roma s/n Oviedo, 33011 Asturias, Spain.

${ }^{3}$ Department of Microbiology and Biochemistry of Dairy Products, Instituto de Productos Lácteos de Asturias - Consejo Superior de Investigaciones Científicas (IPLACSIC), Paseo Río Linares s/n Villaviciosa, 33300 Asturias, Spain.

${ }^{4}$ Institute of Food Science Research (CIAL), CSIC-UAM, CEI UAM-CSIC, c/ Nicolás Cabrera 9 Madrid, 28049 Madrid, Spain.

${ }^{5}$ Group Basic and translational research in inflammatory diseases, Instituto de Investigación Sanitaria del Principado de Asturias (ISPA), Avda. Roma s/n Oviedo, 33011 Asturias, Spain.

\section{Corresponding author}

*Sonia González. Phone: +(34)985104209; Fax: +(34)985103534. E-mail:

soniagsolares@uniovi.es. 


\section{ABSTRACT}

2 Although most of the health effects attributed to polyphenols may be linked to their 3 phenolic-derived metabolites, the role of the intestinal derived-phenolics in human health

4 is still far from being well understood. We determined the profile of fecal phenolic-derived 5 metabolites, microbiota, biomarkers of oxidative stress and inflammation, and daily intake

6 of bioactive compounds in 71 elderly volunteers. Phenylacetic and phenylpropionic acids

7 were the main phenolic metabolites present in feces. From them, phenylacetic acid was

8 related with a more pro-oxidant and immune stimulated status, and both were negatively 9 associated with fecal propionate, whereas phenylpropionic acid was directly related with 10 the fecal concentration of acetate. Moreover, phenylacetic acid was negatively associated 11 with the Bacteroides group and Clostridium cluster XIVa and positively with 12 Lactobacillus. These results provide a rationale to explore the potential of fecal microbial 13 phenolic-derived metabolites as possible biomarkers of health status in future studies 14 focused on the elderly population.

\section{KEYWORDS}

16 Polyphenols; fecal phenolic derived-metabolites; gut microbiota; short chain fatty acids; 17 biomarkers. 


\section{INTRODUCTION}

Dietary (poly)phenols are bioactive compounds of vegetal origin that have been receiving considerable deal of attention from the scientific community in the last years. Most of the mechanisms proposed for their putative protective effects against the development of several chronic conditions such as cardiovascular diseases ${ }^{1-4}$ or cancers ${ }^{5-8}$ are based on their role as scavengers of free radicals but also on their capability to reduce host cellular proliferation and to act as anti-inflammatory agents ${ }^{9-11}$. Polyphenols present in foods are poorly absorbed in the small intestine and a substantial proportion of them reach the colon after digestion where, by de-esterification, hydrogenation, demethylation and/or dehydroxylation, they are transformed by the microbiota into different derived metabolites of low molecular weight, ${ }^{12-14}$ which are often better absorbed than the parent compounds.

There is an increasing body of evidence suggesting that a significant part of the health effects attributed to fruits, vegetables or drinks such as red wine, coffee or tea may be linked to their polyphenol content through their phenolic-derived intestinal microbial metabolites, not occurring preformed in the diet. ${ }^{15}$ In this regard, changes in the phenolic profile of human feces have been reported after the intake of polyphenol-rich foods such as red wine, ${ }^{13,16}$ pomegranate juice, ${ }^{17}$ raspberry, ${ }^{18}$ or following supplementation with isoflavones. ${ }^{19}$ The results obtained so far evidenced a considerable inter- and intraindividual variation in the biological response to polyphenols, that could be attributed to the different dietary patterns and to the existing diversity in the colonic microbiota of the different subjects ${ }^{13,16,19,20}$.

However, while it has been reported that dietary polyphenols can inhibit certain intestinal pathogenic microorganisms ${ }^{16,21}$ and/or stimulate the proliferation of specific beneficial microbes, ${ }^{21}$ thus contributing to the maintenance of a healthy microbial balance in the gut, ${ }^{14}$ there is still scarce information in the literature regarding the interrelationship between the intestinal phenolic compounds and the whole intestinal microbiota. Some 
44 previous in vitro studies have shown that the concentrations of benzoic acid, phenylacetic 45 acid, phenylpropionic acid and 3-(3'-hydroxyphenyl)-propionic acid quantified in human 46 fecal water were present at levels large enough to influence intestinal bacterial growth. ${ }^{22}$ 47 Then, the characterization of the fecal microbial-derived phenolic metabolites is of interest 48 for a better understanding of the metabolism of phenolic compounds by gut bacteria and its 49 consequences for human health.

50 Our aim in the present work was to examine the fecal phenolic profile in the feces of a 51 sample of mature subjects without a declared pathology, and to determine their possible 52 associations with fecal microbiota. We have also evaluated whether the excretion of 53 phenolic catabolites was influenced by fibers and dietary phenolic compounds as well as 54 their possible association with serum parameters related with oxidative stress, 55 inflammation and immune status. This global and multidisciplinary approach could be of 56 help for advancing in the knowledge about the effect of polyphenols on human health, by 57 means of generating new hypotheses that could be tested in future studies. 


\section{MATERIALS AND METHODS}

59

60

61

62

63

\section{Participants}

The sample of the study includes seventy-one healthy, mature volunteers (51 women and 20 men; $70.83 \pm 11.12$ years old) recruited between 2010 and 2012 in the Asturias region (North of Spain), without previous diagnosis of cancer, autoimmune or gastrointestinal diseases, and neither consumption of antibiotics or probiotics/prebiotics one month prior to the study. All subjects were mentally and physically capable to participate in the study and gave informed written consent. Ethical approval was obtained from the Regional Ethics Committee for Clinical Research (Servicio de Salud del Principado de Asturias, Ref. no. 17/2010), in compliance with the Declaration of Helsinki.

\section{Nutritional assessment}

Dietary intake has been registered by a personal interview using an annual, semi quantitative Food Frequency Questionnaire (FFQ) which has been designed ad hoc for the purpose of this study and validated for dietary fibers and polyphenols by means of a $24 \mathrm{~h}$ recall method. During a personalized interview, volunteers were asked, by expert dieticians, item by item, whether they usually ate each food and, if so, how much they ate. Methodological issues concerning dietary assessment have been described previously. ${ }^{23}$ Food intake was analyzed for energy, macronutrients, and total dietary fiber content by using the nutrient Food Composition Tables developed by the Centro de Enseñanza Superior de Nutrición Humana y Dietética (CESNID). ${ }^{24}$ Also, the following fiber components were ascertained using the Marlett et al. food composition tables ${ }^{25}$ : soluble fiber, soluble pectin, soluble hemicellulose, insoluble fiber, insoluble pectin, insoluble hemicellulose, Klason lignin, and cellulose, based on the enzymatic-chemical method developed by Theander et al. by which pectin content is determined using calorimetric assay, cellulose and hemicellulose are determined by high-performance liquid chromatography (HPLC), ${ }^{26}$ and Klason lignin is estimated as the insoluble material after a 
84 Saeman acid hydrolysis. ${ }^{27}$ The polyphenols content in foods was completed using the

85 Phenol Explorer database that contains detailed information from over 400 foods

86 consumed regularly in European countries ${ }^{28}$ and data about the oxygen radical absorbance

87 capacity (ORAC) of foods was obtained from the database from the ORAC of select foods

88 from USDA. ${ }^{29}$ During the personal interview, information was also collected on potential

89 confounders such as smoking habits ("Do you smoke?"), alcohol intake ("How much

90 alcohol do you consume during the day?") or physical activity ("How many time do you

91 spent daily on physical activity?), previously associated with phenolic excretion, ${ }^{30}$ and

92 regarding bowel habits by registering the number of depositions per week and the

93 consistence of feces.

94 Height of the participants was measured using a stadiometer with an accuracy of $\pm 1 \mathrm{~mm}$

95 (Año-Sayol, Barcelona, Spain). The subjects stood barefoot, in an upright position and

96 with the head positioned in the Frankfort horizontal plane. Weight was measured on a scale

97 with an accuracy of \pm 100 g (Seca, Hamburg, Germany). Body mass index (BMI) was

98 calculated using the formula: weight $(\mathrm{Kg}) /$ height $(\mathrm{m})^{2}$.

\section{Blood biochemical analyses}

100

101

102

103

104

105

An overnight fast blood sample was drawn by venepuncture after a 12-hour fast and collected in separate tubes for serum and plasma. Samples were kept on ice and centrifuged $(1000 \times \mathrm{g}, 15$ minutes $)$ within $2-4$ hours after collection. Plasma and serum aliquots were kept at $-20{ }^{\circ} \mathrm{C}$ until analyses were performed. Serum glucose, serum total cholesterol, serum HDL-cholesterol, serum LDL-cholesterol and serum triglycerides were determined by using an automated biochemical auto-analyser.

Total antioxidant capacity (TAC) in serum was determined by the colorimetric assay P40117 (Innoprot, Innovative Technologies in Biological Systems, Vizcaya, Spain). This method determines the conversion of, $\mathrm{Cu}^{2+}$ to $\mathrm{Cu}^{+}$by serum small molecules and proteins. 
109 The reduced ion is chelated with a colorimetric probe, giving a broad absorbance peak

110 around $450 \mathrm{~nm}$, which is proportional to the TAC. ${ }^{31}$ Serum malondialdehyde (MDA)

111 concentrations were determined by the spectrophotometric method of lipid peroxidation

112 LPO-586 (Byoxytech, Oxis International, Portland, OR). ${ }^{32}$ Serum levels of C-reactive 113 protein (CRP) were determined by CRP Human Instant ELISA (eBioscience, San Diego, 114 CA). Levels of serum IL-10, IL-8, IL-17, TNF- $\alpha$, and IL-12 were quantified by flow 115 cytometry using a multiplex immunoassay (Cytometric Bead Array, CBA, BD 116 Biosciences). The concentration of transforming growth factor (TGF- $\beta$ ) was determined by 117 ELISA (BD OptEIA ${ }^{\mathrm{TM}}$, BD Biosciences).

\section{$118 \quad$ Fecal samples collection and processing}

119 Feces were collected in an interval of 7 days after the nutritional interviews. Fresh samples 120 were collected, placed in a sterile container (provided to the volunteers by the research 121 team, together with sterile tools to facilitate sample management) and immediately frozen 122 at $-20{ }^{\circ} \mathrm{C}$ (in the home freezer). Then, the samples were transferred (frozen at $-80{ }^{\circ} \mathrm{C}$ ) to 123 the laboratory. ${ }^{33,34}$ Prior to analyses fecal samples were melted, one gram of sample was 124 weighed, diluted 1:10 in sterile phosphate-buffered saline solution (PBS) and homogenized 125 in a Lab-Blender 400 stomacher (Seward Medical, London, UK) at full speed for 4 min. 126 One $\mathrm{mL}$ of the homogenized samples was centrifuged $\left(10,000 \mathrm{~g}, 30 \mathrm{~min}, 4{ }^{\circ} \mathrm{C}\right)$. The pellet 127 obtained was then used for fecal microbiota DNA extraction whereas the supernatant was 128 filtered through $0.2 \mu \mathrm{m}$ filters, mixed with $1 / 10$ of ethyl butyric acid $(1 \mathrm{mg} / \mathrm{mL})$ as an 129 internal standard and stored at $-80{ }^{\circ} \mathrm{C}$ until gas chromatography (GC) analyses were 130 performed. Sample preparation was carried out in duplicate.

\section{Fecal microbiota analyses}

132 Fecal DNA was obtained from by using the QIAamp DNA stool mini kit (Qiagen, Hilden, 133 Germany) as previously described. ${ }^{34}$ PCR amplification and detection of the 16S rRNA 
134

135

136

137

138

139

140

141

142

143

144

145

146

147

148

149

150

151

152

153

154

155

156

157

158

gene for the quantification of different bacterial groups (Akkermansia, BacteroidesPrevotella-Porphyromonas group, Bifidobacterium, Clostridium cluster XVIa, Lactobacillus group and Faecalibacterium) was performed in a 7,500 Fast Real-Time PCR System (Applied Biosystems, Foster City, CA, USA) using the SYBR Green PCR Master Mix (Applied Biosystems) as described before. ${ }^{35}$ Samples were analysed in duplicate in two independent PCR runs.

\section{Short fatty acids analyses}

Analysis of SCFA (acetate, propionate, isobutyrate, butyrate, and isovalerate) was performed in a gas chromatograph 6890N (Agilent Technologies Inc, Palo Alto, CA, USA) connected to a mass spectrometry (MS) $5973 \mathrm{~N}$ detector (Agilent Technologies) and to a flame ionization detector (FID) as described previously. ${ }^{36}$

\section{Targeted analysis of phenolic metabolites in feces}

For sample preparation, frozen fecal samples were thawed at room temperature, and one gram was taken, diluted $1 / 10$ in sterile phosphate-buffered saline solution (PBS; $0.01 \mathrm{M}$ phosphate buffer, $0.0027 \mathrm{M}$ potassium chloride, $0.137 \mathrm{M}$ sodium chloride, $\mathrm{pH}$ 7.4, prepared from tablets from Sigma-Aldrich), and homogenized in a LabBlender 400 stomacher (Seward Medical, London, U.K.) at full speed for 4 min. Supernatants were then obtained by centrifugation $\left(10000 \mathrm{~g}, 30 \mathrm{~min}, 4^{\circ} \mathrm{C}\right)$ and filtration through $0.2 \mu \mathrm{m}$ and stored at $-20{ }^{\circ} \mathrm{C}$ until analysis. An internal standard 4-hydroxybenzoic-2,3,5,6-d4 acid solution (Sigma-Aldrich, St. Louis, MO) $[1250 \mu \mathrm{g} / \mathrm{mL}$ in formic acid/acetonitrile (1:200, $\mathrm{v} / \mathrm{v})]$ was added to the samples in a proportion 1:5 (v/v). Sample preparation was carried out in duplicate.

For the analysis of phenolic metabolites in the fecal solutions, a previously reported UPLC-ESI-MS/MS method was followed, ${ }^{16,37}$ with some modifications. The limit of detection of phenolic acids by this UPLC-TQMS equipment is up to $0.001 \mu \mathrm{g} / \mathrm{mL}^{38}$ The 
159

160

161

162

163

164

165

166

167

168

169

170

171

172

173

174

175

176

177

178

179

180

181

182

183

184

liquid chromatographic system was a Waters Acquity UPLC (Milford, MA) equipped with a binary pump, an autosampler thermostated at $10{ }^{\circ} \mathrm{C}$, and a heated column compartment $\left(40{ }^{\circ} \mathrm{C}\right.$ ). The column employed was a BEH-C18, $2.1 \times 100 \mathrm{~mm}$ and $1.7 \mu \mathrm{m}$ particle size, from Waters (Milford, MA, USA). The mobile phases were $0.1 \%(\mathrm{v} / \mathrm{v})$ formic acid in water (A) and $0.1 \%(\mathrm{v} / \mathrm{v})$ formic acid in acetonitrile (B). The gradient program was as follows: $0 \mathrm{~min}, 0.1 \% \mathrm{~B}$; $1.5 \mathrm{~min}, 0.1 \% \mathrm{~B} ; 11.17 \mathrm{~min}, 16.3 \% \mathrm{~B} ; 11.5 \mathrm{~min}, 18.4 \% \mathrm{~B} ; 14$ $\min , 18.4 \% \mathrm{~B} ; 14.1 \min , 99.9 \% \mathrm{~B} ; 15.5 \min , 99.9 \% \mathrm{~B}$; $15.6 \mathrm{~min}, 0.1 \% \mathrm{~B}$. Equilibrium time was $2.4 \mathrm{~min}$, resulting in a total run time of $18 \mathrm{~min}$. The flow rate was set constant at $0.5 \mathrm{~mL} / \mathrm{min}$, and the injection volume was $2 \mu \mathrm{L}$. The LC effluent was pumped to an Acquity TQD tandem quadrupole mass spectrometer equipped with a Z-spray electrospray ionization (ESI) source operated in negative polarity mode. The ESI parameters were set as follows: capillary voltage, $3 \mathrm{kV}$; source temperature, $130{ }^{\circ} \mathrm{C}$; desolvation temperature, 400 ${ }^{\circ} \mathrm{C}$; desolvation gas $\left(\mathrm{N}_{2}\right)$ flow rate, $750 \mathrm{~L} / \mathrm{h}$; cone gas $\left(\mathrm{N}_{2}\right)$ flow rate, $60 \mathrm{~L} / \mathrm{h}$. For quantification purposes, data were collected in the multiple reaction monitoring (MRM) mode, tracking the transition of parent and product ions specific to each compound. The MS/MS parameters (cone voltage, collision energy, and MRM transition) of the 62 phenolic compounds targeted in the present study (mandelic acids, benzoic acids, phenols, hippuric acids, phenylacetic acids, phenylpropionic acids, cinnamic acids, 4hydroxyvaleric acids, and valerolactones) were previously reported. ${ }^{16}$ The ESI was operated in negative ionization mode, except for $\gamma$-valerolactone (positive mode). All metabolites were detected using the calibration curves of their corresponding standards, commercially available from different suppliers (Sigma-Aldrich Chemical Co., St. Louis, MO; Phytolab, Vestenbergsgreuth, Germany; and Extrasynthese, Genay, France), except for 4-hydroxy-5-(4'-hydroxyphenyl)valeric and 4-hydroxy-5-(3',4'dihydroxyphenyl)valeric acids, which were quantified using the calibration curves of 3-(4'hydroxyphenyl)- propionic and 3-(3',4'-dihydroxyphenyl)propionic acids, respectively. 
185 Data acquisition and processing was realized with MassLynx 4.1 software. Results are 186 expressed as the amount $(\mu \mathrm{g})$ of phenolic metabolites in $1 \mathrm{~mL}$ of decimal fecal dilutions. 187 All analyses were performed in duplicate.

188

189

190

191

192

193

194

195

196

197

198

199

200

201

\section{Statistical analyses}

IBM-SPSS version 22.0 (SPSS-Inc., Chicago) was used for statistical analyses. Goodness of fit to normal distribution was analyzed with the Kolmogorov-Smirnov test. When the distribution of variables was skewed, the natural logarithm of each value was used in the statistical test. The variable total phenolic metabolite was calculated by the sum of the fecal compounds detectable in at least 35 subjects of the sample. A Student's t-test was used to evaluate the differences in continuous variables according to the tertile of total phenolic metabolite content in feces, whilst categorical variables were examined using chisquared analysis. Also, the linear trend between these variables was explored by means of linear regression analysis adjusting for age, BMI, energy intake, and physical activity as covariates. To deepen into the associations between the diet and the excretion of major phenolic metabolites in feces, a Spearman correlation analysis was conducted. Heatmap was generated under $\mathrm{R}$ version 3.3 .3 package heatmap.2. The conventional probability value for significance (0.05) was used in the interpretation of results. 
RESULTS

The main phenolic metabolites determined by UPLC-ESI-MS/MS in feces were phenylacetic and phenylpropionic acids, accounting, on average, for 46.7 and $35.4 \%$, respectively, of the total phenolic metabolites excreted in feces. For analyzing the data, the sample was divided according to the levels of total phenolic metabolites excreted in feces into tertiles: high (tertile 3), medium (tertile 2), and low (tertile 1) (Table 1). The general characteristics of the sample population were similar across the tertiles, with the exception of the contribution of proteins and lipids to the total energy intake, which was higher for both macronutrients in the individuals included in tertile 1 (lowest total phenolic excretory levels in Table 1). As expected from the division of the sample in tertiles, the levels of the majority phenolic compounds, i.e. phenylacetic and phenylpropionic acids, and to a lesser extent 3-(3'-hydroxyphenyl) propionic acid, displayed a clear trend to increase from tertile 1 to tertile 3, with statistically significant differences among tertiles (Table 2). However, such trend was not so clear for the minority metabolites determined (Table 2). This prompted us to focus on the majority phenolic metabolites: phenylacetic, phenylpropionic and 3-(3'-hydroxyphenyl) propionic acids.

Then, we looked for a possible association between the intestinal microbial groups and SCFA quantified, with the three-major fecal phenolic metabolites as well as with the total phenolics content excreted in feces (Table 3). Total phenolic metabolite content was inversely associated with the fecal levels of Bacteroides group, Clostridium cluster XIVa and propionate, and directly related with Lactobacillus group and acetate. Phenylacetic acid showed a negative association with Bacteroides group and Clostridium cluster XIVa and propionate, and was positively related with Lactobacillus group. An inverse association was also found between phenylpropionic acid excretion and the levels of propionate, while this phenolic metabolite showed a direct association with acetate. In 
227 addition, 3-(3'-hydroxyphenyl) propionic acid was inversely related with isovalerate 228 levels.

229 Linear regression analyses were also conducted in order to investigate the possible 230 associations between the excretion of phenolic metabolites and some blood biomarkers 231 (Table 4). The results obtained pointed to a direct association of TGF- $\beta$, IL-17 and IL-8 232 levels with the total phenolics excretion in feces, with independence of age, energy intake, 233 physical activity and BMI. Protocatechuic and phthalic acids have shown a positive 234 relationship with TGF- $\beta$, and phthalic acid with IL-8. The excretion of phenylacetic acid 235 was directly related with serum biomarkers such as MDA and C-reactive protein, and with 236 immune parameters as TGF- $\beta$, IL-10, IL-17 and IL-8.

237 To deepen into the possible associations between the majority fecal phenolics excretion 238 and diet, we looked for correlations between the main fecal phenolic metabolites, and the 239 intake of dietary compounds (Figure 1). Phenylacetic acid was inversely related with the 240 intake of some flavonoids and phenolic acids and showed a positive association with 241 isoflavonoids, kaempferol 3-O-glucoside, kaempferol 3-O-xylosyl-glucoside, kaempferol 242 3-O-acetyl-glucoside, procyanidin dimer B5 and p-coumaroylquinic acid. Whereas 243 phenylpropionic acid was directly associated with the intake of different proanthocyanidins 244 and soluble fiber, 3-(3'-hydroxyphenyl) propionic acid was related with insoluble fibers, 245 flavones and flavanols. The total fecal phenolic metabolite content showed a directly 246 correlation only with kaempferol 3-O-glucoside. Moreover, the dietary polyphenols, 247 statistically related with phenolic excretion, were directly associated with the intake of 248 different types of fibers

(Figure 2). 


\section{DISCUSSION}

250

251

252

253

254

255

256

257

258

259

260

261

262

263

264

265

266

267

Our data provide new and valuable information about the link between the major phenolic metabolites in feces and the gut microbiota composition in the context of a low-grade prooxidant and pro-inflammatory status of the host, as frequently occurs at advanced age.

It is not completely clear how changes in the profile and levels of fecal phenolic metabolites may be related to their biological effects. In this sense, there is a general consensus in the literature supporting the importance of the aqueous phase components of the human feces for modulating the colonic environment, ${ }^{39,40}$ the profile and levels of phenolics being a direct indicator of the microbial phenolic degradation products. ${ }^{41}$ However, to be effective at the physiological level it is necessary that phenolics are absorbed and reach target tissues. Nonetheless, the absorption of phenolics is difficult to predict from the excreted fraction, since they only represent the metabolites nonabsorbed. ${ }^{42}$ To date, some authors have suggested that higher total phenolic excretion in feces could be directly related with a higher concentration of these bioactive compounds at the intestinal level ${ }^{43}$ which would imply a greater protection against oxidative stress and the action of potential carcinogens. ${ }^{12}$ From the analytic point of view, stool is an easily accessible and non-invasive matrix with metabolites originating from host, its gut microbiota, and food components. Therefore, analysis of stool samples is a good approach to ascertain how phenolic profile and content in intestinal fluids can be influenced by the diet. $^{44}$ Since not all phenolic-derived metabolites are augmented in the feces of those individuals displaying the highest total phenolic excretory levels as compared to the excretors of lower levels, it is possible that differential effects among the distinct fecal phenolics could exist. From the evaluated metabolites, phenylacetic and phenylpropionic acids were by far the most abundant. Thus, hereinafter we will focus our discussion on these two metabolites, considered individually, and their possible differential impact on human health. In agreement with previous studies from other authors, ${ }^{45,46}$ we identified 
275 phenylacetic acid as the most abundant phenolic metabolite in human feces, explaining 276 approximately the $45 \%$ of the total phenolic excretion.

277 Whereas other phenolic metabolites in feces are predominantly derived from the microbial 278 metabolism of polyphenols contained in vegetable foodstuffs, phenylacetic acid is mostly 279 derived from the intestinal microbial fermentation of aromatic amino acids, particularly 280 phenylalanine through the phenylpropanoid pathway ${ }^{47}$ as well as from endogenous 281 production. ${ }^{37}$ The association of phenylacetic acid with a more pro-oxidant and pro282 inflammatory status found in the present work supports our previous results suggesting an 283 association of this phenolic acid with variables related with an "unhealthy lifestyle" and 284 obesity $^{30}$. At this point, it may be interesting to consider whether the higher fecal levels of 285 this compound could be the cause or the reflection of a pro-inflammatory status. Based on 286 evidences provided by other authors, the last option seems plausible since the pro287 inflammatory status often observed in relation with advanced age (the so-called 288 inflammaging) has been shown to be associated with an altered tyrosine metabolism in 289 elderly persons. ${ }^{48}$ Phenylacetic acid is an endogenous intermediate catabolite of 290 phenylalanine and therefore, variations in the levels of phenylacetic acid could be 291 reflecting changes in the endogenous amino acids metabolism. On the other hand, 292 increased levels of phenylalanine at the expenses of tyrosine have been associated with a 293 chronic low-grade inflammation in elderly persons, ${ }^{48}$ thus providing a link between 294 phenylacetic acid and the immune status of mature adults. In this scenario, we wanted to 295 examine whether the differences in phenylacetic acid excretion could be also related with 296 diet and the intestinal microbiota profile. Data available in the literature concerning the 297 phenolic metabolites produced by microbial colonic degradation are scarce. However, the association found by us between the intake of procyanidin dimer-B5 and phenylacetic acid excretion is in consonance with the direct association between the fecal levels of lactobacilli and this phenolic metabolite, and with previous data by other authors reporting 
301

302

303

304

305

306

307

that some microorganisms from the genus Lactobacillus are able to transform procyanidins with a lower degree of polymerization into phenylacetic acid. ${ }^{49}$

On the other hand, supporting the evidences about the impact of the daily intake of polyphenols on the gut microbiota, modulating its composition and/or functionality, ${ }^{50}$ we have found a positive association between phenylpropionic acid and the intake of different proantocyanidins and soluble fiber. Considering the high correlation found by us between most of these dietary compounds and soluble fibers (i.e.: narigenin $r=0.670$, apigenin $\mathrm{r}=0.538$, lariciresinol $\mathrm{r}=0.713,5$-caffeoylquinic acid $\mathrm{r}=0.304,(-)$-epicatechin-3-O-gallate $\mathrm{r}=0.388, \mathrm{p} \leq 0.01$, Figure 2), it might be possible that fibers could interact with the fecal microbial metabolism of these phenolics by increasing the levels of proanthocyanidins reaching the colon, thus favoring their metabolization by the intestinal microbiota and the formation of SCFA. ${ }^{51-53}$ Finally, an inverse association between the concentration in feces of total phenolic metabolites, and the concentration of propionate and levels of Bacteroides group and the Clostridium cluster XIVa, was found in the present work. In this regard, reduced levels of the major butyrate producer microorganisms in the human colon (Clostridium cluster IV that includes Faecalibacterium genus, and Clostridium cluster $\mathrm{XIVa)}$ as well as of the genus Bacteroides has been repeatedly reported situations in which the oxidative status may be altered. ${ }^{54-57}$ Moreover, alterations on fecal levels of Bacteroides and butyrate-producing bacteria as well as increased levels of Lactobacillus have been recently communicated by us in over-weight and obese individuals from the general population that also presented a more pro-oxidant and pro-inflammatory status. ${ }^{58}$ In addition, an intestinal microbiota imbalance has been linked with some states associated to obesity and insulin resistance in which the relative proportion of acetate is increased, ${ }^{59,60}$ similarly as to what occurs in the present work for the positive association found between total fecal phenolic-derived compounds and fecal acetate concentration. In contrast to what has been indicated so far, Russell et al. ${ }^{47}$ have reported that microbial protein fermentation 
327 is the likely source of phenylacetic acid and other phenylpropanoid-derived metabolites in

328 the human colon, aromatic amino acid-metabolizing activity being particularly prevalent

329 among Bacteroides spp. and to a considerable lesser extent among some members of the

330 Clostridium cluster XIVa. ${ }^{47}$ Therefore, the inverse association found by us between fecal

331 phenylacetic acid and these two microbial groups and propionic acid (a metabolite mainly

332 produced by Bacteroides) could also be due to variations in the metabolic activity among

333 the microbiotas of individuals as related to the fecal phenolics profile. ${ }^{61}$

334 This study presents some strengths and limitations that deserve additional comment. The

335 holistic approach and the use of well-validated and efficient UPLC-MS methodologies for

336 fecal metabolite analysis are strengths of the present study. On the other hand, although

337 FFQ has a limited capacity for accurately quantify the daily intake, it is however at present

338 the most suitable method available to describe regular dietary habits. ${ }^{62}$ This aspect is of 339 great importance for the study of the relationship between diet and the microbial intestinal 340 environment since usual diets are known to be the main drivers that shape the microbial 341 composition and metabolic activity of the intestinal ecosystem. Giving the transversal 342 design of the present study, a directionality in the observed associations cannot be 343 established. Nevertheless, we have identified two main different metabolic profiles as 344 related with the differential excretion of total fecal phenolic compounds and their 345 association with serum biomarkers and with gut microbial composition. This opens the 346 possibility of designing future studies in order to explore the potential of phenylacetic and 347 phenylpropionic acids as possible biomarkers of health status and/or as markers of the 348 individual gut microbiota composition and functionality in both health and illness states. 349 This would help in reinforcing the promotion and maintenance of a healthy status through 350 diet. 
351

352

353

354

355

356

357

\section{ABBREVIATIONS USED}

BMI, body mass index; CESNID, Centro de Enseñanza Superior de Nutrición Humana y Dietética; ESI, Z-spray electrospray ionization; FID, flame ionization detector; FFQ, food frequency questionnaire; GC, gas chromatography; HPLC, high-performance liquid chromatography; MDA, malondialdehyde; MS, mass spectrometry; ORAC, oxygen radical absorbance capacity; PBS, phosphate-buffered saline; PCR, C-reactive protein; SCFA, short chain fatty acids; TAC, total antioxidant capacity; TGF- $\beta$, transforming growth factor, UPLC-ESI-MS/MS, ultraperformance liquid chromatography coupled with electrospray ionization tandem mass spectrometry.

\section{FUNDING SOURCES}

This work was funded by the Spanish MINECO (AGL2015-64522-C2-R) and Comunidad de Madrid (ALIBIRD-CM S2013/ABI-2728), the grant GRUPIN 14-043 "Microbiota humana, Alimentación y Salud" from "Plan Regional de Investigación del Principado de Asturias" and by a grant from Biopolis SL, with the framework of the e-CENIT Project SENIFOOD from the Spanish Ministry of Science and Innovation. Nuria Salazar benefits from a Juan de la Cierva postdoctoral Trainee Program of the Spanish Ministry of Economy and Competitiveness (MINECO).

\section{CONFLICT OF INTEREST STATEMENT}

On behalf of all authors, the corresponding author states that there are no conflicts of interest. 
371

372

373

374

375

376

377

378

379

380

381

382

383

384

385

386

387

388

389

390

391

392

393

394

395

\section{REFERENCES}

(1) Tressera-Rimbau, A.; Arranz, S.; Eder, M.; Vallverdú-Queralt, A. Dietary Polyphenols in the prevention of stroke. Oxid Med Cell Longev. 2017, 2017, 7467962.

(2) Lamuela-Raventos, R. M.; Quifer-Rada, P. Effect of dietary polyphenols on cardiovascular risk. Heart. 2016, 102, 1340-1341.

(3) Vetrani, C.; Vitale, M.; Bozzetto, L.; della Pepa, G.; Cocozza, S.; Costabile, G.; Mangione, A.; Cipriano, P.; Annuzzi, G.; Rivellese, A.A. Association between different dietary polyphenol subclasses and the improvement in cardiometabolic risk factors: evidence from a randomized controlled clinical trial. Acta Diabetol. 2017, $55,149-153$.

(4) Murillo, A.G.; Fernández, M.L. The relevance of dietary polyphenols in cardiovascular protection. Curr. Pharm. Des. 2017, 23, 2444-2452.

(5) Sharma, A.; Kaur, M.; Katnoria, J.K.; Nagpal, A.K. Polyphenols in food: cancer prevention and apoptosis induction. Curr. Med. Chem. 2017. doi: $10.2174 / 0929867324666171006144208$.

(6) Zamora-Ros, R.; Béraud, V.; Franceschi, S.; Cayssials, V.; Tsilidis, K. K.; BoutronRuault, M. C.; Weiderpass, E.; Overvad, K.; Tjønneland, A.; Eriksen, A. K.; Bonnet, F.; Affret, A.; Katzkem V.; Kühn, T.; Boeing, H.; Trichipoulou, A.; Valanou, E.; Karakatsani, A.; Masala, G.; Grioni, S.; Santucci de Magistris, M.; Tumino, R.; Ricceri, F.; Skeie, G.; Parr, C.L.; Merino, S.; Salamanca-Fernandez, E.; Chirlaque, M.D.; Ardanaz,E.; Amiano, P.; Almquist, M.; Drake, I.; Hennings, J.; Sandström, M.; Bueno-de-Mesquita, H.B.A.; Peeters, P.h.; Khaw, K.T.; Wareham, N.J.; Schmidt, J.A.; Perez-Cornago, A.; Aune, D.; Riboli, E.; Slimani, N.; Scalbert, A.; Romieu, I.; Agudo, A. Rinaldi, S. Consumption of fruits, vegetables and fruit 
396

juices and differentiated thyroid carcinoma risk in the European Prospective Investigation into Cancer and Nutrition (EPIC) Study. Int. J. Cancer 2018, 142, $449-459$.

(7) Russo, G. I.; Campisi, D.; Mauro, M. Di; Regis, F.; Reale, G.; Marranzano, M.; Ragusa, R.; Solinas, T.; Madonia, M.; Cimino, S.; Morgia, G. Dietary Consumption of Phenolic Acids and Prostate Cancer: A Case-Control Study in Sicily, Southern Italy. Molecules 2017, 22, pii:E2159.

(8) Metere, A.; Giacomelli, L. Absorption, metabolism and protective role of fruits and vegetables polyphenols against gastric cancer. Eur. Rev. Med. Pharmacol. Sci. 2017, $21,5850-5858$.

(9) Bravo, L. Polyphenols: Chemistry, dietary sources, metabolism, and nutrional significance. Nutr. Rev. 1998, 56, 317-333.

(10) Scalbert, A.; Manach, C.; Morand, C.; Remesy, C.; Jimenez, L. Dietary polyphenols and the prevention of diseases. Crit Rev.Food Sci.Nutr. 2005, 45, 287-306.

(11) del Rio, D.; Rodriguez-Mateos, A.; Spencer J.P.E.; Tognolini, M.; Borges, G.; Crozier, A. Dietary (poly)phenolics in human health: structures, bioavailability, and evidence of protective effects against chronic diseases. Antioxid Redox Signal. 2013, $18,1818-1892$.

(12) Scalbert, A.; Morand, C.; Manach, C.; Rémésy, C. Absorption and metabolism of polyphenols in the gut and impact on health. Biomed. Pharmacother. 2002, 56, 276282.

(13) Jiménez-Girón, A.; Muñóz-Gonzalez, I.; Martin-Álvarez, P.J.; Moreno-Arribas, M.V; Bartolomé, B. Towards the fecal metabolome derived from moderate red wine intake. Metabolites. 2014, 4, 1101-1118. 
420

421

422

423

424

425

(14) Parkar, S.G.; Trower, T.M.; Stevenson, D. E. Fecal microbial metabolism of polyphenols and its effects on human gut microbiota. Anaerobe 2013, 23, 12-19.

(15) Williamson, G.; Clifford, M.N. Colonic metabolites of berry polyphenols: the missing link to biological activity? Br J Nutr. 2010, 104 (Suppl.3), S48-66.

(16) Jiménez-Girón, A.; Queipo-Ortuño, M.I.; Boto-Ordóñez, M.; Muñoz-González, I.; Sánchez-Patán, F.; Monagas, M.; Martín-Álvarez, P.J.; Murri, M.; Tinahones, F.J.; Andrés-Lacueva, C.; Bartolomé, B., Moreno-Arribas, M.V. Comparative study of microbial-derived phenolic metabolites in human feces after intake of gin, red wine, and dealcoholized red wine. J. Agric. Food Chem. 2013, 61, 3909-3915.

(17) Mosele, J.I.; Gosalbes, M.J.; Macià, A.; Rubió, L.; Vázquez-Castellanos, J.F.; Jiménez Hernández, N.; Moya, A.; Latorre, A.; Motilva, M.J. Effect of daily intake of pomegranate juice on fecal microbiota and feces metabolites from healthy volunteers. Mol. Nutr. Food Res. 2015, 59, 1942-1953.

(18) Gill, C.I.; McDougall, G.J.; Glidewell, S.; Stewart, D.; Shen, Q.; Tuohy, K.; Dobbin, A.; Boyd, A.; Brown, E.; Haldar, S.; Rowland, I.R. Profiling of phenols in human fecal water after raspberry supplementation. J.Agric Food Chem. 2010, 58, 10389-10395.

(19) Guadamuro, L.; Jiménez-Girón, A.M.; Delgado, S.; Florez, A.B.; Suárez, A.; Martin-Álvarez, P.J.; Bartolomé, B.; Moreno-Arribas, M.V; Mayo, B. Profiling of phenolic metabolites in feces from menopausal women after long-term isoflavone supplementation. J.Agric Food Chem. 2016, 64, 210-216.

(20) Gross, G.; Jacobs, D.M.; Peters, S.; Possemiers, S.; van, D.J.; Vaughan, E.E.; van de Wiele, T. In vitro bioconversion of polyphenols from black tea and red wine/grape juice by human intestinal microbiota displays strong interindividual variability. J.Agric Food Chem. 2010, 58, 10236-10246. 
445

(21) Dueñas, M.; Muñóz-González, I.; Cueva, C.; Jiménez-Girón, A.; Sánchez-Patán, F.; Santos-Buelga, C.; Moreno-Arribas, M. V; Bartolomé, B. A survey of modulation of gut microbiota by dietary polyphenols. Biomed.Res Int. 2015, 2015,850902.

(22) Jenner, A.M.; Rafter, J.; Halliwell, B. Human fecal water content of phenolics: the extent of colonic exposure to aromatic compounds. Free Radic. Biol. Med. 2005, 38, $763-772$.

(23) Cuervo, A.; Valdés, L.; Salazar, N.; de los Reyes-Gavilán, C.G.; Rúas-Madiedo, P.; Gueimonde, M.; González, S. Pilot study of diet and microbiota: interactive associations of fibers and polyphenols with human intestinal bacteria. J. Agric. Food Chem. 2014, 62, 5330-5336.

(24) Centro de Enseñanza Superior de Nutrición Humana y Dietética (CESNID). Tablas de Composición de Alimentos por Medidas Caseras de Consumo Habitual en España (Food composition tables in household measures commonly consumed in Spain); McGrawHill, Publicaciones y Ediciones de la Universidad de Barcelona: Barcelona, Spain, 2008.

(25) Marlett, J.A.; Cheung, T.F. Database and quick methods of assessing typical dietary fiber intakes using data for 228 commonly consumed foods. J. Am. Diet Assoc. 1997, 97, 1139-1148,1151.

(26) Theander, O.; Westerlund, E.A. Studies on dietary fiber, 3: improved procedures for analysis of dietary fiber. J. Agric. Food Chem. 1986, 34, 330-336.

(27) Seaman, J.F. Kinetics of wood saccharification: hydrolysis of cellulose and decomposition of sugars in dilute acid at high temperature. Ind. Eng. Chem. 1945, $37,43-52$.

(28) Neveu, V.; Pérez-Jimenez, J.; Vos, F.; Crespy, V.; du Chaffaut, L.; Mennen, L.; 
Knox, C.; Eisner, R.; Cruz, J.; Wishart, D.; Scalbert, A. Phenol-Explorer: an online comprehensive database on polyphenol contents in foods. Database. 2010, 2010, bap024.

(29) United States Deparment of Agriculture (USDA). Database for the Oxygen Radical Absorbance Capacity (ORAC) of Selected Foods, Release 2. US Dep. Agric. 2017. URL (http://www.ars.usda.gov/ba/bhnrc/ndl) (accessed on 15 July 2018).

(30) Gutiérrez-Díaz, I.; Fernández-Navarro, T.; Salazar, N.; Bartolomé, B.; MorenoArribas, M. V.; De Andrés-Galiana, E. J.; Fernández-Martínez, J. L.; De Los ReyesGavilán, C. G.; Gueimonde, M.; González, S. Adherence to a Mediterranean Diet influences the fecal metabolic profile of microbial-derived phenolics in a spanish cohort of middle-age and older people. J. Agric. Food Chem. 2017, 65, 586-595.

(31) Apak, R.; Guclu, K.; Ozyurek, M.; Karademir, S.E.; Altun, M. Total antioxidant capacity assay of human serum using copper(II)-neocuproine as chromogenic oxidant: the CUPRAC method. Free Radic. Res. 2005, 39, 949-961.

(32) Gérard-Monnier, D.; Erdelmeier, I.; Regnard, K.; Moze-Henry, N.; Yadan, J.C.; Chaudiere, J. Reactions of 1-methyl-2-phenylindole with malondialdehyde and 4hydroxyalkenals. Analytical applications to a colorimetric assay of lipid peroxidation. Chem. Res. Toxicol. 1998, 11, 1176-1183.

(33) Hevia, A.; Milani, C.; López, P.; Cuervo, A.; Arboleya, S.; Duranti, S.; Turroni, F.; González, S.; Suárez, A.; Gueimonde, M.; Ventura, M.; Sánchez, B.; Margolles, A. Intestinal dysbiosis associated with Systemic Lupus Erythematosus. MBio. 2014, $5, \mathrm{e} 01548-14$

(34) Salazar, N.; López, P.; Valdés, L.; Margolles, A.; Suárez, A.; Patterson, A.M.; Cuervo, A.; de los Reyes-Gavilán, C.G.; Rúas-Madiedo, P.; González, S.; Gueimonde, M. Microbial targets for the development of functional foods 
494

495

496

497

498

499

500

501

502

503

504

505

506

507

508

509

510

511

512

513

514

515

516

517

accordingly with nutritional and immune parameters altered in the elderly. J. Am. Coll. Nutr. 2013, 32, 399-406.

(35) Arboleya, S.; Binetti, A.; Salazar, N.; Fernández, N.; Solis, G.; HernándezBarranco, A.; Margolles, A.; de los Reyes-Gavilán, C.G.; Gueimonde, M. Establishment and development of intestinal microbiota in preterm neonates. FEMS Microbiol. Ecol. 2012, 79, 763-772.

(36) Salazar, N.; Gueimonde, M.; Hernández-Barranco, A. M.; Rúas-Madiedo, P.; de los Reyes-Gavilán, C.G. Exopolysaccharides produced by intestinal Bifidobacterium strains act as fermentable substrates for human intestinal bacteria. Appl. Environ. Microbiol. 2008, 74, 4737-4745.

(37) Muñóz-González, I.; Jiménez-Girón, A.; Martín-Álvarez, P.J.; Bartolomé, B.; Moreno-Arribas, M.V. Profiling of microbial-derived phenolic metabolites in human feces after moderate red wine intake. J. Agric. Food Chem. 2013, 61, 94709479.

(38) Sánchez-Patán, F.; Monagas, M.; Moreno-Arribas, M.V; Bartolomé, B. Determination of microbial phenolic acids in human faeces by UPLC-ESI-TQ MS. J. Agric. Food Chem. 2011, 59, 2241-2247.

(39) Rafter, J.J.; Child, P.; Anderson, A.M.; Alder, R.; Eng, V.; Bruce, W.R. Cellular toxicity of fecal water depends on diet. Am. J. Clin. Nutr. 1987, 45, 559-563.

(40) Nordling, M.M.; Glinghammar, B.; Karlsson, P.C.; De Kok, T.M.C.M.; Rafter, J. J. Effects on cell proliferation, activator protein-1 and genotoxicity by fecal water from patients with colorectal adenomas. Scand. J. Gastroenterol. 2003, 38, 549-555.

(41) Jaganath, I.B.; Mullen, W.; Lean, M.E.J.; Edwards, C.A.; Crozier, A. In vitro catabolism of rutin by human fecal bacteria and the antioxidant capacity of its 
catabolites. Free Radic. Biol. Med. 2009, 47, 1180-1189.

519

520

521

522

(42) Monagas, M.; Urpi-Sarda, M.; Sánchez-Patán, F.; Llorach, R.; Garrido, I.; GómezCordoves, C.; Andrés-Lacueva, C.; Bartolomé, B. Insights into the metabolism and microbial biotransformation of dietary flavan-3-ols and the bioactivity of their metabolites. Food Funct. 2010, 1, 233-253.

(43) Santos-Buelga, C.; Scalbert, A. Proanthocyanidins and tannin-like compounds Nature, occurrence, dietary intake and effects on nutrition and health. J. Sci. Food Agric. 2000, 80, 1094-1117.

(44) Smirnov, K. S.; Maier, T. V.; Walker, A.; Heinzmann, S. S.; Forcisi, S.; Martinez, I.; Walter, J.; Schmitt-Kopplin, P. Challenges of metabolomics in human gut microbiota research. Int J Med Microbiol 2016, 306, 266-279.

(45) Jenner, A.M.; Rafter, J.; Halliwell, B. Human fecal water content of phenolics: the extent of colonic exposure to aromatic compounds. Free Radic. Biol. Med. 2005, $38,763-772$.

(46) Russell, W.R.; Gratz, S.W.; Duncan, S.H.; Holtrop, G.; Ince, J.; Scobbie, L.; Duncan, G.; Johnstone, A.M.; Lobley, G.E.; Wallace, R.J.; Duthie, G.G.; Flint, H.J. High-protein, reduced-carbohydrate weight-loss diets promote metabolite profiles likely to be detrimental to colonic health. Am. J. Clin. Nutr. 2011, 93, 1062-1072.

(47) Russell, W.R.; Duncan, S.H.; Scobbie, L.; Duncan, G.; Cantlay, L.; Calder, A.G.; Anderson, S.E.; Flint, H.J. Major phenylpropanoid-derived metabolites in the human gut can arise from microbial fermentation of protein. Mol. Nutr. Food Res. 2013, 57, 523-535.

(48) Capuron, L.; Schroecksnadel, S.; Féart, C.; Aubert, A.; Higueret, D.; BarbergerGateau, P.; Layé, S.; Fuchs, D. Chronic low-grade inflammation in elderly persons 
542

is associated with altered tryptophan and tyrosine metabolism: role in neuropsychiatric symptoms. Biol. Psychiatry 2011, 70, 175-182.

(49) Li, S.; Chen, L.; Yang, T.; Wu, Q.; Lv, Z.; Xie, B; Sun, Z. Increasing antioxidant activity of procyanidin extracts from the pericarp of Litchi chinensis processing waste by two probiotic bacteria bioconversions. J. Agric. Food Chem. 2013, 61, 2506-2512.

(50) Tomás-Barberan, F.A.; Selma, M.V.; Espín, J.C. Polyphenols' gut microbiota metabolites: bioactive or biomarkers? J. Agric. Food Chem. 2018, 66, 3593-3594.

(51) Scalbert, A.; Déprez, S.; Mila, I.; Albrecht, A.M.; Huneau, J.F.; Rabot, S. Proanthocyanidins and human health: systemic effects and local effects in the gut. Bio. Factors. 2000, 13, 115-20.

(52) Ge, Z.Z.; Dong, X.Q.; Zhu, W.; Zhang, Y.; Li, C.M. Metabolites and changes in antioxidant activity of A-type and B-type proanthocyanidin dimers after incubation with rat intestinal microbiota. J. Agric. Food Chem. 2015, 63, 8991-8998.

(53) Gil-Sánchez, I.; Esteban-Fernández, A.; González de Llano, D.; Sanz-Buenhombre, M.; Guadarrana, A.; Salazar, N.; Gueimonde, M.; de los Reyes-Gavilán, C.G.; Martín-Gómez, L.; García-Bermejo, M.L.; Bartolomé, B.; Moreno-Arribas, M.V. Supplementation with grape pomace in healthy women: changes in biochemical parameters, gut microbiota and related metabolic biomarkers. J. Funct. Foods. 2018, $45,34-36$.

(54) Song, H.; Yoo, Y.; Hwang, J.; Na, Y.C.; Kim, H.S. Faecalibacterium prausnitzii subspecies-level dysbiosis in the human gut microbiome underlying atopic dermatitis. J. Allergy Clin. Immunol. 2016, 137, 852-860.

(55) Zhou, Y.; Zhi, F. Lower level of Bacteroides in the gut microbiota is associated with 
566

567

568

569

570

571

572

573

574

575

576

577

578

579

580

581

582

583

584

585

586

587 inflammatory bowel disease: a meta-analysis. Biomed. Res. Int. 2016, 2016, 5828959. doi: $10.1155 / 2016 / 5828959$.

(56) Schaffler, H.; Herlemann, D.P.; Alberts, C.; Bodammer, P.; Bannert, K.; Köller, T.; Kreikemeyer, B.; Lamprecht, G. Mucosa-attached bacterial community in Crohn's disease coheres with the Clinical Disease Activity Index. Environ. Microbiol. Rep. 2016. doi:10.1111/1758-2229.12411.

(57) Teixeira, T.F.S.; Grzeskowiak, L.M.; Salminen, S.; Laitinen, K.; Bressan, J.; Gouveia Peluzio Mdo, C. Faecal levels of Bifidobacterium and Clostridium coccoides but not plasma lipopolysaccharide are inversely related to insulin and HOMA index in women. Clin. Nutr. 2013, 32, 1017-1022.

(58) Fernández-Navarro, T.; Salazar, N.; Gutiérrez-Díaz, I.; de los Reyes-Gavilán, C.G.; Gueimonde, M.; González, S. Different intestinal microbial profile in Over-Weight and obese subjects consuming a diet with low content of fiber and antioxidants. Nutrients. 2017, 9, pii:E551.

(59) Salazar, N.; Dewulf, E.M.; Neyrinck, A.M.; Bindels, L.B.; Cani, P.D.; Mahillon, J.; de Vos, W.M.; Thissen, J.P.; Gueimonde, M.; de los Reyes-Gavilán, C.G.; Delzenne, N.M. Inulin-type fructans modulate intestinal Bifidobacterium species populations and decrease fecal short-chain fatty acids in obese women. Clin. Nutr. 2015, 34, 501-507.

(60) Saad, M.J.A.; Santos, A.; Prada, P.O. Linking gut microbiota and inflammation to obesity and insulin resistance. Physiology 2016, 31, 283-293.

(61) Reichardt, N.; Duncan, S.H.; Young, P.; Belenguer, A.; McWilliam-Leitch, C.; Scott, K.P.; Flint, H.J.; Louis, P. Pylogenic distribution of three pathways for propionate production within the human gut microbiota. ISME J. 2014, 8, 13231335. 
591 (62) Wu, G.D.; Chen, J.; Hoffmann, C.; Bittinger, K.; Chen, Y.Y.; Keilbaugh, S.A.;

Bewtra, M.; Knights, D.; Walters, W.A.; Knight, R.; Sinha, R.; Gilroy, E.; Gupta,

K.; Baldassano, R.; Nessel, L.; Li, H.; Bushman, F.D.; Lewis, J.D. Linking longterm dietary patterns with gut microbial enterotypes. Science. 2011, 334,105-108. 
Figure 1. Spearman correlation between those major fecal phenolic metabolites $(\mu \mathrm{g} / \mathrm{mL})$ whose concentration differed significantly among tertiles, with dietary polyphenols (mg/day) and fibers (g/day). Columns correspond to fecal microbial metabolites; rows correspond to dietary compounds. Blue and red colors denote negative and positive association, respectively. The intensity of the colors represents the degree of association between these phenolic compounds determined in feces and several dietary compounds and asterisk indicate significant associations: ${ }^{*} \mathrm{p}<0.05 ; * * \mathrm{p} \leq 0.01$.

Figure 2. Spearman correlation between dietary polyphenols (mg/day) and the different classes and subclasses of dietary fibers (g/day). Columns correspond to the different classes of fibers; rows correspond to dietary polyphenols. Blue and red colors denote negative and positive association, respectively. The intensity of the colors represents the degree of association between variables and asterisk indicate significant associations: $* p<0.05 ; * * p \leq 0.01$. Only significant results were presented. 


\section{TABLES}

Table 1. General Characteristics of the Sample According to the Tertiles Formed Considering the

Total Phenolic Metabolite Content in Feces ${ }^{\mathrm{a}}$.

total phenolic metabolite content $(\mu \mathrm{g} / \mathrm{mL})$

\begin{tabular}{|c|c|c|c|}
\hline & \multicolumn{3}{|c|}{ total phenolic metabolite content $(\mu \mathrm{g} / \mathrm{mL})$} \\
\hline & tertile $1^{\mathrm{b}}(\mathrm{n}=24)$ & tertile $2^{\mathrm{c}}(\mathrm{n}=23)$ & tertile $3^{\mathrm{d}}(\mathrm{n}=24)$ \\
\hline age (y) & $73.0 \pm 12.6_{a}$ & $69.4 \pm 11.1_{\mathrm{a}}$ & $70.0 \pm 9.8 \mathrm{a}$ \\
\hline female ( $\%$ of subjects) & $66.7_{\mathrm{a}}$ & $78.3_{\mathrm{a}}$ & $70.8_{\mathrm{a}}$ \\
\hline $\mathrm{BMI}^{\mathrm{e}}\left(\mathrm{kg} / \mathrm{m}^{2}\right)$ & $27.7 \pm 4.5_{\mathrm{a}}$ & $26.1 \pm 3.1_{\mathrm{a}}$ & $28.1 \pm 4.1_{\mathrm{a}}$ \\
\hline sedentary lifestyle ( $\%$ of subjects) & $54.2_{\mathrm{a}}$ & $52.2_{\mathrm{a}}$ & $66.7_{\mathrm{a}}$ \\
\hline non-smoker ( $\%$ of subjects) & $70.8_{a}$ & $65.2_{\mathrm{a}}$ & $83.3_{\mathrm{a}}$ \\
\hline deposition (times/week) & $5.7 \pm 2.1_{\mathrm{a}}$ & $6.4 \pm 2.3_{\mathrm{a}}$ & $6.6 \pm 2.3_{\mathrm{a}}$ \\
\hline \multicolumn{4}{|l|}{ blood parameters } \\
\hline serum glucose $(\mathrm{mg} / \mathrm{dL})$ & $98.9 \pm 18.6_{a}$ & $98.5 \pm 17.1_{\mathrm{a}}$ & $105.7 \pm 32.3_{\mathrm{a}}$ \\
\hline total cholesterol $(\mathrm{mg} / \mathrm{dL})$ & $212.5 \pm 34.5 \mathrm{a}$ & $217.6 \pm 47.5_{a}$ & $224.6 \pm 41.8 \mathrm{a}$ \\
\hline $\operatorname{HDL}$ cholesterol $^{\mathrm{f}}(\mathrm{mg} / \mathrm{dL})$ & $53.1 \pm 11.1_{\mathrm{a}}$ & $54.1 \pm 15.7_{\mathrm{a}}$ & $52.8 \pm 12.4_{a}$ \\
\hline LDL-cholesterol $^{\mathrm{g}}(\mathrm{mg} / \mathrm{dL})$ & $138.5 \pm 29.4_{a}$ & $140.4 \pm 39.4_{a}$ & $143.7 \pm 36.5_{\mathrm{a}}$ \\
\hline Ttriglycerides (mg/dL) & $104.2 \pm 30.4_{\mathrm{a}}$ & $115.3 \pm 51.1_{\mathrm{a}}$ & $140.6 \pm 63.2_{\mathrm{a}}$ \\
\hline $\mathrm{TAC}^{\mathrm{h}}(\mathrm{mM})$ & $0.3 \pm 0.1_{\mathrm{a}, \mathrm{b}}$ & $0.3 \pm 0.1_{\mathrm{a}}$ & $0.4 \pm 0.1_{\mathrm{b}}$ \\
\hline $\operatorname{MDA}^{\mathrm{i}}(\mu \mathrm{M})$ & $2.3 \pm 0.6_{a}$ & $2.2 \pm 0.5_{\mathrm{a}}$ & $2.5 \pm 0.6_{a}$ \\
\hline $\operatorname{CRP}^{\mathrm{j}}(\mathrm{pg} / \mathrm{mL})$ & $1.2 \pm 1.3_{\mathrm{a}}$ & $0.9 \pm 0.8_{\mathrm{a}}$ & $1.6 \pm 1.2_{\mathrm{a}}$ \\
\hline \multicolumn{4}{|l|}{ diet } \\
\hline energy intake (kcal/day) & $1842.7 \pm 445.9_{\mathrm{a}}$ & $1790.5 \pm 425.9_{\mathrm{a}}$ & $1851.7 \pm 627.6_{a}$ \\
\hline carbohydrates ( $\%$ of total energy) & $39.3 \pm 5.7 \mathrm{a}$ & $40.2 \pm 6.4_{a}$ & $42.5 \pm 6.7_{\mathrm{a}}$ \\
\hline lipids ( $\%$ of total energy) & $38.9 \pm 3.9_{\mathrm{a}}$ & $38.6 \pm 6.8_{\mathrm{a}, \mathrm{b}}$ & $35.6 \pm 5.8_{\mathrm{b}}$ \\
\hline proteins ( $\%$ of total energy) & $20.9 \pm 3.6_{a}$ & $18.7 \pm 2.4_{b}$ & $19.3 \pm 2.7_{\mathrm{a}, \mathrm{b}}$ \\
\hline polyphenols (mg/day) & $1338.1 \pm 1268.2_{\mathrm{a}}$ & $1690.8 \pm 1081.4_{a}$ & $1592.2 \pm 1292.3_{\mathrm{a}}$ \\
\hline fiber (g/day) & $19.1 \pm 7.5_{\mathrm{a}}$ & $18.6 \pm 6.2_{\mathrm{a}}$ & $21.15 \pm 10.4_{a}$ \\
\hline insoluble fiber (g/day) & $11.9 \pm 5.6_{a}$ & $11.4 \pm 4.3_{\mathrm{a}}$ & $13.9 \pm 6.4_{a}$ \\
\hline $\operatorname{ORAC}^{\mathrm{k}}\left(\mu \mathrm{mol} \mathrm{TE}{ }^{\mathrm{l}} /\right.$ day $)$ & $7096.7 \pm 6185.2_{a}$ & $7387.9 \pm 6256.1_{a}$ & $7300.4 \pm 7910.6_{a}$ \\
\hline
\end{tabular}

${ }^{a}$ Results derived from Student's $t$-test are presented as estimated marginal mean \pm standard deviation and differences in categorical variables are examined using chi-squared analysis and presented as percentage (\%). Range of phenolics in feces according to tertiles: ${ }^{b}$ tertile $1(3.0-15.9 \mu \mathrm{g} / \mathrm{mL}),{ }^{c}$ tertile $2(15.9-22.7 \mu \mathrm{g} / \mathrm{mL})$ and tertile $3(22.7-109.0 \mu \mathrm{g} / \mathrm{mL})$. Different subscript letters indicate significant statistical differences $(\mathrm{p} \leq 0.05)$. ${ }^{\mathrm{e}} \mathrm{BMI}$, body mass index. ${ }^{\mathrm{f}} \mathrm{HDL}$, high-density lipoprotein. ${ }^{\mathrm{g}} \mathrm{LDL}$, low-density lipoprotein. ${ }^{\mathrm{h}} \mathrm{TAC}$, total antioxidant capacity. ${ }^{\mathrm{i}} \mathrm{MDA}$, malondialdehyde. ${ }^{\mathrm{j}} \mathrm{CRP}, \mathrm{C}$-reactive protein. ${ }^{\mathrm{k}} \mathrm{ORAC}$, oxygen radical absorbance capacity. ${ }^{\text {TE}}$, Trolox equivalents. 
Table 2. Concentration of the Major Fecal Phenolic Metabolites in the Population According to the Tertiles Formed Considering the Total Phenolic Excretion Levels ${ }^{\mathbf{a}}$.

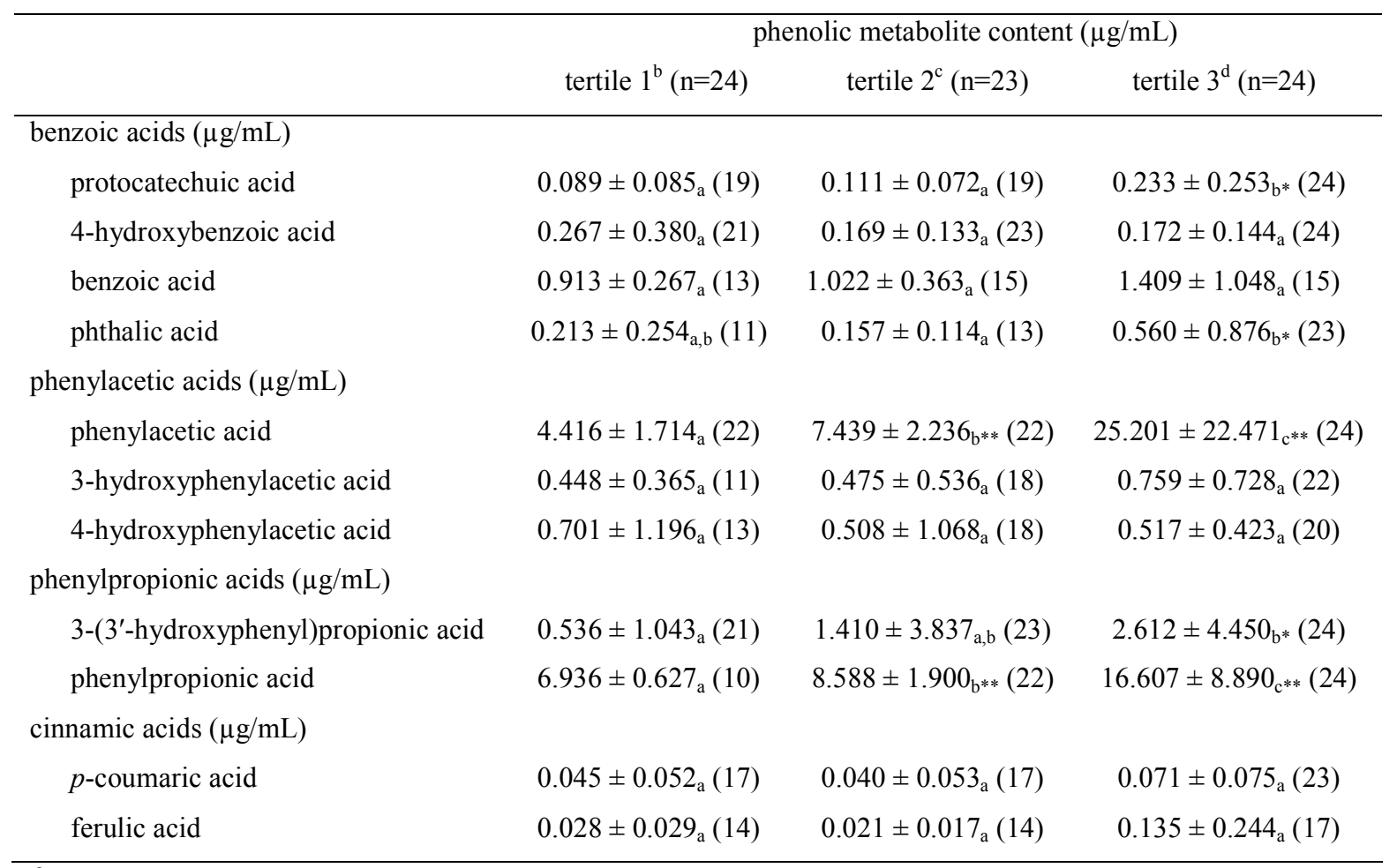

${ }^{a}$ Results derived from Student's $t$-test are presented as estimated marginal mean \pm standard deviation. Range of phenolic metabolites in feces according to tertiles: ${ }^{b}$ tertile $1(3.0-15.9 \mu \mathrm{g} / \mathrm{mL})$, ${ }^{c}$ tertile $2(15.9-22.7 \mu \mathrm{g} / \mathrm{mL})$ and ${ }^{\mathrm{d}}$ tertile $3(22.7-109.0 \mu \mathrm{g} / \mathrm{mL})$. Different subscript letters indicate significant statistical differences. ${ }^{*} \mathrm{p} \leq 0.05 ; * * \mathrm{p} \leq 0.01$. 
Table 3. Lineal Regression Analysis between the Fecal Microbial Groups and Short-Chain Fatty Acids (SCFA) and the Excretion of those Fecal

Phenolic Metabolites whose Concentration Differed Significantly among Tertiles ${ }^{\mathrm{a}}$.

\begin{tabular}{|c|c|c|c|c|c|c|c|c|c|c|c|c|}
\hline & \multicolumn{2}{|c|}{$\begin{array}{l}\text { total phenolic content } \\
(\mu \mathrm{g} / \mathrm{mL})\end{array}$} & \multicolumn{2}{|c|}{$\begin{array}{l}\text { phenylacetic } \\
\text { acid }(\mu \mathrm{g} / \mathrm{mL})\end{array}$} & \multicolumn{2}{|c|}{$\begin{array}{l}\text { 3-(3'-hydroxyphenyl) } \\
\text { propionic acid }(\mu \mathrm{g} / \mathrm{mL})\end{array}$} & \multicolumn{2}{|c|}{$\begin{array}{c}\text { phenylpropionic acid } \\
(\mu \mathrm{g} / \mathrm{mL})\end{array}$} & \multicolumn{2}{|c|}{$\begin{array}{l}\text { protocatechuic acid } \\
(\mu \mathrm{g} / \mathrm{mL})\end{array}$} & \multicolumn{2}{|c|}{$\begin{array}{c}\text { phthalic acid } \\
(\mu \mathrm{g} / \mathrm{mL})\end{array}$} \\
\hline & $\mathrm{R}^{2 \mathrm{~b}}$ & $\beta^{\mathrm{c}}$ & $\mathrm{R}^{2}$ & $\beta$ & $\mathrm{R}^{2}$ & $\beta$ & $\mathrm{R}^{2}$ & $\beta$ & $\mathrm{R}^{2}$ & $\beta$ & $\mathrm{R}^{2}$ & $\beta$ \\
\hline \multicolumn{13}{|c|}{ Microbiota $^{\mathrm{d}}$ (Log No. Cells per Gram feces) } \\
\hline Akkermansia & 0.233 & -0.079 & 0.257 & 0.047 & 0.204 & -0.122 & 0.101 & -0.197 & 0.118 & -0.004 & 0.237 & 0.184 \\
\hline $\begin{array}{l}\text { Bacteroides-Prevotella- } \\
\text { Porphyromonas }\end{array}$ & & $-0.592 *$ & & $-0.675^{*}$ & & -0.258 & & -0.157 & & -0.082 & & $-0.650^{*}$ \\
\hline Bifidobacterium & & 0.429 & & 0.489 & & 0.276 & & 0.040 & & 0.102 & & 0.437 \\
\hline Clostridium cluster XIVa & & $-0.475 *$ & & $-0.491 *$ & & -0.176 & & -0.193 & & -0.238 & & $-0.539 *$ \\
\hline Lactobacillus group & & $0.578^{*}$ & & $0.555^{*}$ & & 0.262 & & 0.268 & & 0.052 & & 0.481 \\
\hline Faecalibacterium prausnitzii & & 0.044 & & -0.033 & & 0.111 & & 0.091 & & 0.086 & & 0.022 \\
\hline \multicolumn{13}{|l|}{$\operatorname{SCFA}^{\mathrm{e}}(\mathrm{mM})$} \\
\hline acetate & 0.397 & $0.715^{* *}$ & 0.351 & 0.404 & 0.380 & 0.137 & 0.442 & $1.021 * *$ & 0.294 & $0.790 * *$ & 0.223 & 0.367 \\
\hline propionate & & $-0.705 * *$ & & $-0.613 *$ & & -0.099 & & $-0.587 *$ & & $-0.839 * *$ & & $-0.756^{*}$ \\
\hline isobutyrate & & 0.421 & & -0.004 & & 0.721 & & 0.768 & & 0.853 & & 0.096 \\
\hline butyrate & & 0.215 & & 0.186 & & 0.454 & & -0.042 & & 0.008 & & 0.248 \\
\hline isovalerate & & -0.040 & & 0.536 & & $-1.239 *$ & & -0.520 & & -0.552 & & 0.241 \\
\hline
\end{tabular}

${ }^{a}$ Results based on lineal regression analysis. ${ }^{b} \mathrm{R}^{2}$, coefficient of multiple determinations. ${ }^{\mathrm{c}} \beta$, standardized regression coefficient. ${ }^{*} \mathrm{p} \leq 0.05$ and $* * \mathrm{p} \leq 0.01$.

${ }^{\mathrm{d}}$ microbiota included: Akkermansia, Bacteroides-Prevotella-Porphyromonas, Bifidobacterium, Clostridium cluster XIVa, Lactobacillus group and Faecalibacterium prausnitzii as factors and age, energy intake, body mass index and physical activity as covariates or alternatively ${ }^{\mathrm{e}} \mathrm{SCFA}$ : acetate, propionate, isobutyrate, butyrate and isovalerate as factors and age, energy intake, body mass index and physical activity as covariates. 
Table 4. Results from the Lineal Regression Analyses in order to Estimate the Relationship between Blood Biomarkers and the Fecal Excretion of

Total and those Fecal Phenolic Metabolites whose Concentration Differed Significantly among Tertiles ${ }^{a}$.

\begin{tabular}{|c|c|c|c|c|c|c|c|c|c|c|c|c|}
\hline & \multicolumn{2}{|c|}{$\begin{array}{l}\text { total phenolic content } \\
\qquad(\mu \mathrm{g} / \mathrm{mL})\end{array}$} & \multicolumn{2}{|c|}{$\begin{array}{c}\text { phenylacetic acid } \\
(\mu \mathrm{g} / \mathrm{mL})\end{array}$} & \multicolumn{2}{|c|}{$\begin{array}{c}3-\left(3^{\prime}-\right. \\
\text { hydroxyphenyl) } \\
\text { propionic acid } \\
(\mu \mathrm{g} / \mathrm{mL})\end{array}$} & \multicolumn{2}{|c|}{$\begin{array}{l}\text { phenylpropionic } \\
\text { acid }(\mu \mathrm{g} / \mathrm{mL})\end{array}$} & \multicolumn{2}{|c|}{$\begin{array}{l}\text { protocatechuic } \\
\operatorname{acid}(\mu \mathrm{g} / \mathrm{mL})\end{array}$} & \multicolumn{2}{|c|}{ phthalic acid $(\mu \mathrm{g} / \mathrm{mL})$} \\
\hline & $\mathrm{R}^{2 \mathrm{~b}}$ & $\beta^{\mathrm{c}}$ & $\mathrm{R}^{2}$ & $\beta$ & $\mathrm{R}^{2}$ & $\beta$ & $\mathrm{R}^{2}$ & $\beta$ & $\mathrm{R}^{2}$ & $\beta$ & $\mathrm{R}^{2}$ & $\beta$ \\
\hline $\mathrm{TAC}^{\mathrm{d}}(\mathrm{mM})$ & 0.104 & 0.143 & 0.124 & 0.119 & 0.157 & 0.026 & 0.048 & 0.140 & 0.091 & -0.070 & 0.098 & -0.044 \\
\hline $\operatorname{MDA}^{\mathrm{e}}(\mu \mathrm{M})$ & 0.128 & 0.264 & 0.194 & $0.370 *$ & 0.156 & 0.009 & 0.031 & -0.030 & 0.097 & -0.132 & 0.116 & 0.180 \\
\hline $\operatorname{CRP}^{\mathrm{f}}(\mathrm{pg} / \mathrm{mL})$ & 0.128 & 0.222 & 0.180 & $0.283 *$ & 0.157 & -0.042 & 0.032 & 0.051 & 0.117 & 0.190 & 0.130 & 0.196 \\
\hline total cholesterol $(\mathrm{mg} / \mathrm{dL})$ & 0.059 & 0.077 & 0.074 & 0.021 & 0.167 & 0.011 & 0.033 & 0.168 & 0.112 & 0.167 & 0.112 & -0.127 \\
\hline HDL-cholesterol $^{\mathrm{g}}(\mathrm{mg} / \mathrm{dL})$ & 0.057 & -0.054 & 0.079 & -0.079 & 0.167 & -0.009 & 0.010 & -0.027 & 0.092 & 0.058 & 0.105 & -0.085 \\
\hline LDL-cholesterol $^{\text {h }}(\mathrm{mg} / \mathrm{dL})$ & 0.058 & 0.060 & 0.074 & 0.022 & 0.167 & -0.027 & 0.029 & 0.150 & 0.124 & 0.199 & 0.105 & -0.080 \\
\hline triglycerides (mg/dL) & 0.076 & 0.158 & 0.083 & 0.100 & 0.186 & 0.150 & 0.035 & 0.171 & 0.098 & -0.103 & 0.110 & -0.111 \\
\hline serum glucose $(\mathrm{mg} / \mathrm{dL})$ & 0.068 & 0.123 & 0.085 & 0.114 & 0.171 & 0.070 & 0.013 & 0.066 & 0.090 & 0.028 & 0.120 & -0.156 \\
\hline $\mathrm{TGF}-\beta^{\mathrm{i}}(\mathrm{pg} / \mathrm{mL})$ & 0.231 & $0.398 * *$ & 0.294 & $0.446 * *$ & 0.162 & 0.081 & 0.044 & 0.123 & 0.164 & $0.291 *$ & 0.209 & $0.351 * *$ \\
\hline IL-10 ${ }^{\mathrm{j}}(\mathrm{pg} / \mathrm{mL})$ & 0.133 & 0.223 & 0.165 & $0.237^{*}$ & 0.156 & -0.005 & 0.039 & 0.096 & 0.096 & 0.101 & 0.097 & -0.031 \\
\hline $\mathrm{IL}-17^{\mathrm{j}}(\mathrm{pg} / \mathrm{mL})$ & 0.142 & $0.244 *$ & 0.173 & $0.254 *$ & 0.156 & -0.005 & 0.041 & 0.105 & 0.100 & 0.119 & 0.097 & -0.026 \\
\hline $\mathrm{IL}-8^{\mathrm{j}}(\mathrm{pg} / \mathrm{mL})$ & 0.143 & $0.353 *$ & 0.179 & $0.385^{*}$ & 0.165 & -0.138 & 0.059 & 0.252 & 0.090 & 0.088 & 0.179 & $0.422 *$ \\
\hline $\mathrm{TNF}-\alpha^{\mathrm{k}}(\mathrm{pg} / \mathrm{mL})$ & 0.088 & -0.060 & 0.111 & -0.003 & 0.156 & 0.002 & 0.054 & -0.173 & 0.086 & -0.005 & 0.100 & -0.070 \\
\hline $\mathrm{IL}-12^{\mathrm{j}}(\mathrm{pg} / \mathrm{mL})$ & 0.113 & -0.185 & 0.126 & -0.135 & 0.156 & 0.008 & 0.075 & -0.236 & 0.094 & -0.099 & 0.106 & -0.111 \\
\hline
\end{tabular}

${ }^{a}$ Results based on lineal regression analysis adjusted by age, energy intake, body mass index and physical activity. ${ }^{b} \mathrm{R}^{2}$, coefficient of multiple determinations. ${ }^{\mathrm{c}} \beta$, standardized regression coefficient. ${ }^{*} \mathrm{p} \leq 0.05$ and ${ }^{* *} \mathrm{p} \leq 0.01$. ${ }^{\mathrm{d}} \mathrm{TAC}$, total antioxidant capacity. ${ }^{\mathrm{e}} \mathrm{MDA}$, malondialdehyde. ${ }^{\mathrm{f}} \mathrm{CRP}, \mathrm{C}-$ reactive protein. ${ }^{\mathrm{g}} \mathrm{HDL}$, high-density lipoprotein. ${ }^{\mathrm{h}} \mathrm{LDL}$, low-density lipoprotein. ${ }^{\mathrm{i}} \mathrm{TGF}$, transforming growth factor. ${ }^{\mathrm{j}} \mathrm{IL}$, interleukin. ${ }^{\mathrm{k}} \mathrm{TNF}$, tumor necrosis factor. 


\section{FIGURE GRAPHICS}

\section{Figure 1}

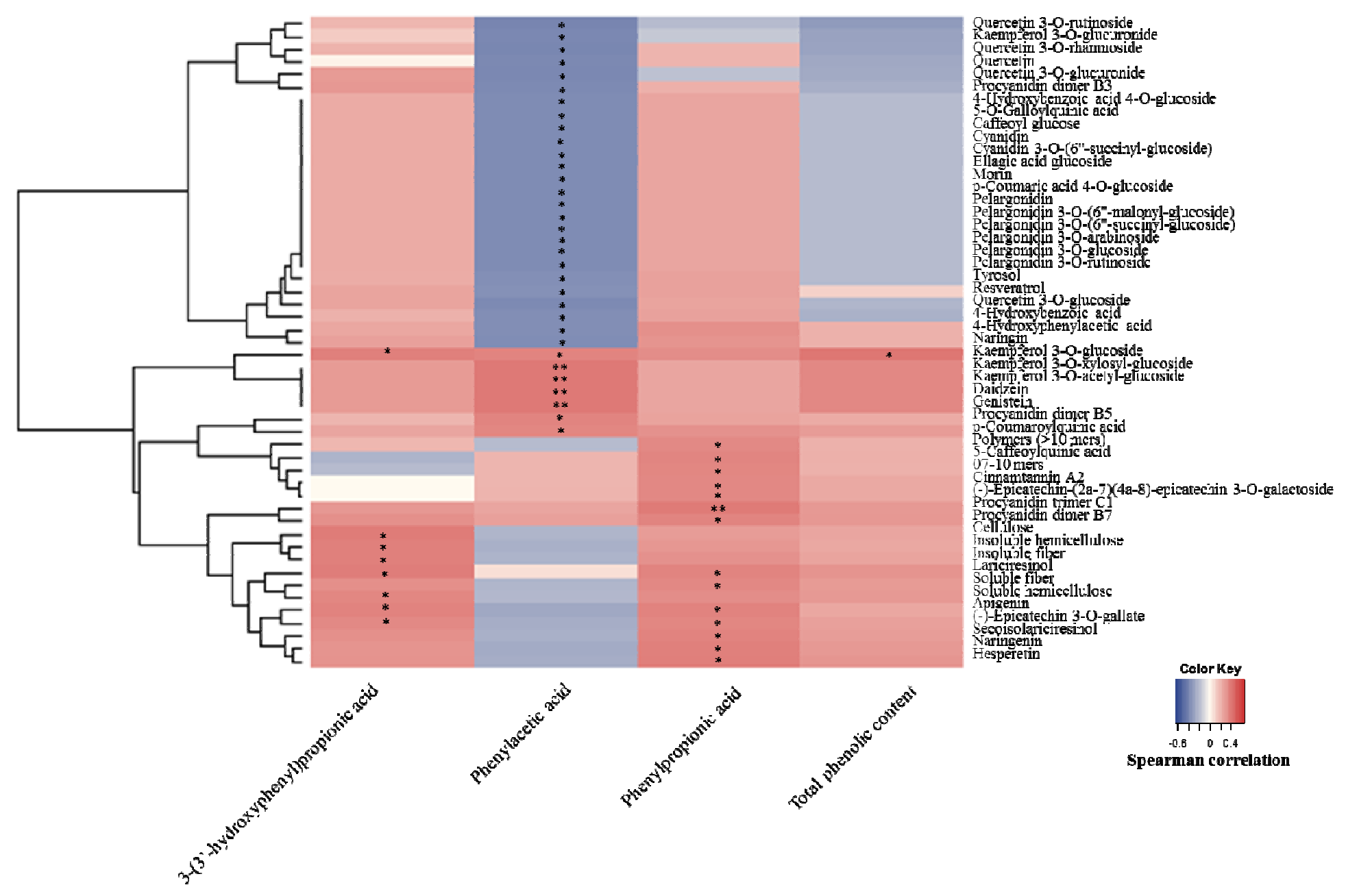


Figure 2

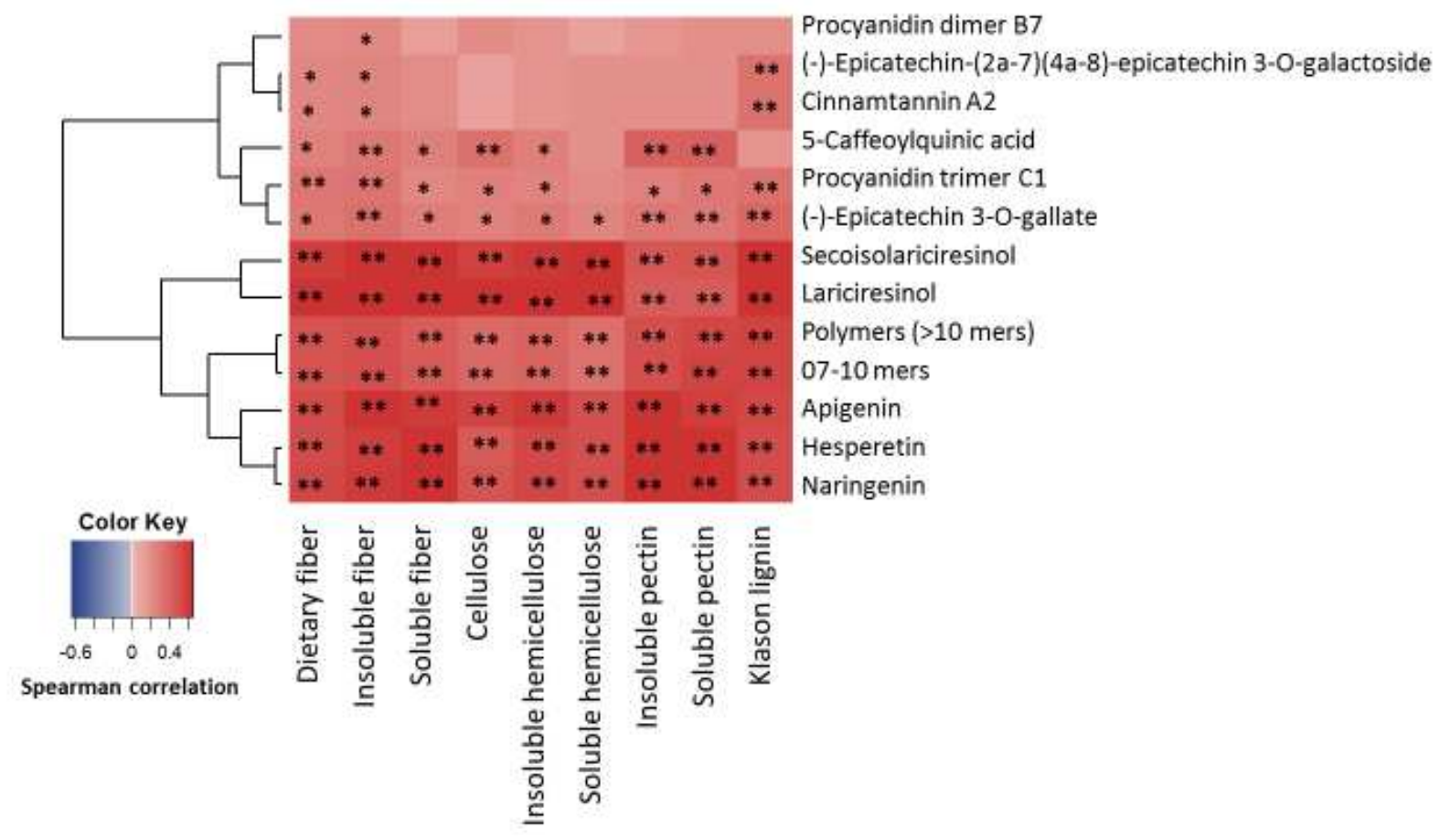




\section{GRAPHIC FOR TABLE OF CONTENTS}

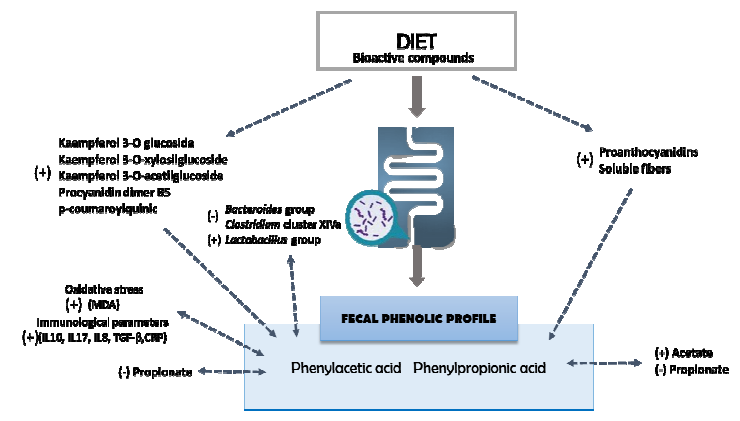

